\title{
Comparative Study of Pseudo-Continuous Anal Sexual Practice among Preparatory School Youths in Dire Dawa City Administration Eastern Ethiopia
}

Mengistu T Alemu ${ }^{1}$, Yadeta Dessie ${ }^{1}, \mathrm{~T}_{\text {Tesfaye }}{ }^{1}$, Abdu Oumer $^{2^{*}}$ and Yohannes Teka ${ }^{3}$

${ }^{1}$ Department of Public Health, Haramaya University, Ethiopia

${ }^{2}$ Department of Public Health, Wolkite University, Ethiopia

${ }^{3}$ Department of Public Health, Debremarkose University, Ethiopia

*Corresponding author: Abdu Oumer, Department of Public Health, Wolkite University, Ethiopia, Tel: + 251911658074; E-mail: phnabu@gmail.com Received date: November 12, 2017; Accepted date: November 24, 2017; Published date: November 28, 2017

Copyright: (c) 2017 Alemu MT, et al. This is an open-access article distributed under the terms of the Creative Commons Attribution License, which permits unrestricted use, distribution, and reproduction in any medium, provided the original author and source are credited.

\begin{abstract}
Background:

Human immunodeficiency virus highly affected young peoples in developing countries, of which sexual transmission was the major route including vaginal, oral and anal sex. Understanding the full range of sexual behavior among young people especially anal sexual experience is very crucial to design appropriate intervention strategies.

\section{Objective:}

To assess oral and anal sexual experience and associated factors among preparatory school youths in Dire Dawa city, Eastern Ethiopia, 2016.

\section{Methods:}

School based cross sectional study was conducted among 1067 school youths attending preparatory schools. Systematic random sampling method was used to select study participants. Data were collected using selfadministered questionnaire and entered in to Epi-data version 3.3.1 and exported to SPSS 20 for analysis. Descriptive and bivariate logistic regression was done. Variables in bivariate analysis with $\mathrm{P}<0.25$ were entered to multiple logistic regression analysis to determine predictor variables. $\mathrm{P}<0.05$ was considered statistically significance and AOR with $95 \% \mathrm{CI}$ used to assess strength of association.
\end{abstract}

\section{Results:}

The proportion of youths who reported having anal sex was $6.7 \%$ (66). Having multiple sexual partnerships was reported by $56.5 \%$ of youths who ever engaged in anal sex. From those who ever engaged to anal sex, $34.8 \%$ consistently used condom. Anal sex experience was significantly associated with intimate partner ever engaged to anal sex ( $A O R=5.34,95 \% C I$ : 4.2-26.98), ever engaged to vaginal sex (AOR=10.64, 95\% CI: 2.39-11.9), ever watching pornographic movies $(\mathrm{AOR}=3.86,95 \% \mathrm{CI}: 1.45-10.29)$ and parental monitoring of youth's sexual behavior $(\mathrm{AOR}=2.63,95 \% \mathrm{CI}: 1.12-6.19)$.

\section{Conclusion:}

Significant proportion of youths had engaged in anal sexual practice and multiple sexual partners were common among youths for anal sex practices. In the contrary consistent condom use was very low. A combination of Sexual health education intervention strategies should be implemented at family, school and community level.

Keywords: Anal sex; School youths; Immunodeficiency; Health

\section{Background}

Sexual engagement has different forms including oral sex, vaginal sex, anal sex and masturbation. Significant proportion of youths engaged in these sexual behaviors in varied level $[1,2]$. Moreover it is known as sexual intercourse was the major transmission route of HIV among the youth population [3].

Young people accounts significant proportion of the population worldwide. Half of the world's population is under 25 years old and young people age and 10-24 years constitute about a third of the SubSaharan Africa (SSA) population [4] meaning that some three and half 
Citation: Alemu MT, Dessie Y, Tesfaye T, Oumer A, Teka Y (2017) Comparative Study of Pseudo-Continuous Anal Sexual Practice among Preparatory School Youths in Dire Dawa City Administration Eastern Ethiopia. J Health Educ Res Dev 5: 240. doi: $10.4172 / 2380-5439.1000240$

Page 2 of 6

billion children and young people are, or will soon be, of reproductive age. Youth age $15-24$ years account $18.2 \%$ of Ethiopia total population based on the 2014 mini Ethiopian demographic and health survey (EDHS) report [5].

This 10-24 yrs age group living in the developing World suffers disproportionately from negative sexual and reproductive health outcomes especially Human immune deficiency virus (HIV/AIDS) $[6,7]$.

Youth females were the most affected about 15\% HIV burden especially in Sub Saharan Africa (SSA) countries [3] and about $0.3 \%$ HIV burden among youths in Ethiopia [8].

The risk of transmission of HIV through unprotected receptive anal sex is 20 times more than through unprotected receptive vaginal sex $(1.7 \%$ vs $0.08 \%)$ [9]. There were an estimated 250000 new HIV infections among adolescents in 2013 [3].

Studies in other parts of the world show that youths practice oral sex in higher rate even more than vaginal sex for many reasons [10,11]. In a study done in Addis Ababa about 5.4\% and 4.3\% of high school youths ever engaged in oral and anal sex respectively [1]. So this study helps to describe the level of anal sex practice by school youths in Dire Dawa city administration so as to design appropriate intervention strategies on sexual behavior of in school youths in the study area.

\section{Objective}

To assess Anal sexual experience and associated factors among preparatory school youths (15-24 years) in Dire Dawa city, Eastern Ethiopia, 2016.

\section{Methods}

\section{Study settings}

The study was conducted in Dire Dawa city administration among preparatory school youths, which is found in Eastern part of Ethiopia $515 \mathrm{kms}$ from Addis Ababa. Dire Dawa is the seat of a city administration that consists of 9 urban and 38 rural kebeles [12]. There were 20 secondary schools, 103 primary schools, $88 \mathrm{KG}$ and 8 preparatory schools in the region (4 private and 4 governmental). A total of 3147 were preparatory school students were registered as of 2014 (Bureau, 2014; Bureau, 2014). Data was conducted from March $1-10,2016$.

\section{Study design}

School based cross sectional quantitative study design was conducted among randomly selected youths attending preparatory schools in Dire Dawa city.

\section{Sample size determination}

The required sample size for the first and second specific objectives was calculated. Taking school youths, age as determinant for anal sex practice, using computer software found minimum sample size of 711 . Considering rare nature of event and design effect of 1.5 was used with final sample size was 1067 school youths were included [1].

\section{Sampling procedure}

All eight preparatory schools in Dire Dawa city administration were included in the study. There were a total of 3147 students in eight preparatory schools. The total sample size was proportionally allocated for each preparatory schools and then again to grade 11 and 12 . Then systematic random sampling technique was used to select the study participants from each grade accordingly.

\section{Data collection techniques}

Data were collected using pretested, adapted, self-administered structured questionnaire from [2]. It was translated into Amharic, Afan-Oromo and Somali languages then further translated back to English. Eight diploma nursing students were recruited to facilitate data collection. Pre-tested was done on 5\% of samples in other institution and the questionnaire was rearranged. Two day training, on site close supervision, daily checkup of the filled questionnaires and feedbacks were carried out. Also double data entry to EpiData and inconsistencies were corrected against hard copy. Anal sex was considered when a man puts his penis in his partner's anus or when one lets their partner insert the penis in their anus" [2]

\section{Data processing and analysis}

Cleaned and checked data was entered in to EpiData Version 3.3.1 and exported to SPSS version 20 for analysis. Simple descriptive statistics such as a frequency distribution and percentages was performed. Binary logistic regression with crude odds ratio and its $95 \%$ CI was computed. Variables with $\mathrm{P}<0.25$ in bivariate analysis were entered to multiple binary logistic regression models to determine predictors of outcome variables. $\mathrm{P}<0.05$ was considered to declare statistical significance. Moreover AOR with their 95\% CI would be used to assess strength of the association.

\section{Results}

\section{Socio-demographic characteristics of school youths}

A total of 983 (92.1\%) response rates were observed. From a total of 983 study participants $513(52.2 \%)$ were male. The mean age of the respondents was $18.63 \pm 1.42 \mathrm{SD}$. Three hundred forty eight $(35.4 \%)$ of respondent were Oromo by ethnicity followed by 320 (32.6\%) Amhara. Four hundred sixty two (47.0\%) were Muslim followed by 433(44.0\%) Orthodox. six hundred twenty four $(63.5 \%)$ of the participants were living with both biological parents and the remaining $262(36.5 \%)$ were living in other living arrangements (Table 1).

\begin{tabular}{|l|l|l|l|}
\hline Variable & Variable category & Number & Percent \\
\hline \multirow{2}{*}{ Age } & $15-19$ yrs & 732 & 74.5 \\
\cline { 2 - 4 } & $20-24$ yrs & 251 & 25.5 \\
\hline \multirow{2}{*}{ Ethnicity } & Oromo & 348 & 35.4 \\
\cline { 2 - 4 } & Amhara & 320 & 32.5 \\
\cline { 2 - 4 } & Somali & 162 & 16.5 \\
\cline { 2 - 4 } & Others & 153 & 15.6 \\
\hline \multirow{2}{*}{ Religion } & Muslim & 462 & 47.0 \\
\cline { 2 - 4 } & Orthodox & 433 & 44.0 \\
\hline
\end{tabular}


Citation: Alemu MT, Dessie Y, Tesfaye T, Oumer A, Teka Y (2017) Comparative Study of Pseudo-Continuous Anal Sexual Practice among Preparatory School Youths in Dire Dawa City Administration Eastern Ethiopia. J Health Educ Res Dev 5: 240. doi: $10.4172 / 2380-5439.1000240$

Page 3 of 6

\begin{tabular}{|l|l|l|l|}
\hline \multirow{2}{*}{} & Protestant & 79 & 8.1 \\
\cline { 2 - 4 } & Other & 9 & 0.9 \\
\hline \multirow{2}{*}{$\begin{array}{l}\text { Living } \\
\text { arrangement }\end{array}$} & With both biological parents & 624 & 63.5 \\
\cline { 2 - 4 } & With one of the biological parent & 210 & 21.4 \\
\cline { 2 - 4 } & Other living arrangements & 52 & 5.3 \\
\hline $\begin{array}{l}\text { Maternal } \\
\text { educational } \\
\text { status }\end{array}$ & Illiterate and none formal education & 540 & 56.1 \\
\cline { 2 - 4 } $\begin{array}{l}\text { Paternal } \\
\text { educational } \\
\text { status }\end{array}$ & Formal education & 423 & 43.9 \\
\cline { 2 - 4 } & Illiterate and none formal education & 294 & 31.1 \\
\hline
\end{tabular}

Table 1: Socio-economic and demographic characteristics of study participants in Dire Dawa city administration Eastern Ethiopia March $01-10 / 2016$.

\section{Sexual Experience of School Youths}

\section{Vaginal sex experience}

Two hundred fifteen $(22.1 \%)$ of the participants had vaginal sex experience and of which $148(73.7 \%)$ start sexual intercourse before age of 18 years old. In other way the median age for first sex was 17 years with inter quartile range of 3 years. Among those having vaginal sexual experience only 88 (44.4\%) were using condoms consistently during vaginal sexual activity.

\section{Anal sex experience}

Out of the total 983 school youths 66 (6.7\%) had ever engaged in anal sex of those who had anal sexual experience only $23(34.8 \%)$ of school youths were using condom consistently. About 44 (65.8\%) and 26 (56.5\%) school youths had multiple sexual partner for oral and anal sex practice respectively (Table 2 ).

\begin{tabular}{|l|l|l|l|}
\hline \multicolumn{2}{|l|}{ Variable } & Number & Percent \\
\hline Ever engaged in anal sex & Yes & 66 & 6.7 \\
\cline { 2 - 4 } & No & 917 & 93.3 \\
\hline \multirow{2}{*}{$\begin{array}{l}\text { Number of anal sex } \\
\text { partner }\end{array}$} & One & 20 & 43.5 \\
\cline { 2 - 4 } & Two or more & 26 & 56.5 \\
\hline \multirow{2}{*}{$\begin{array}{l}\text { Frequency of condom } \\
\text { use during anal sex }\end{array}$} & Always & 23 & 34.8 \\
\cline { 2 - 4 } & Sometimes & 25 & 37.9 \\
\cline { 2 - 4 } & Never & 18 & 27.3 \\
\hline
\end{tabular}

Table 2: Anal sexual experience among preparatory school youths in Dire Dawa city administration, March 01-10/2016 (N=983).

Almost 190 (20\%) of participant's sexual behavior were monitored by parents. Two hundred thirty four (24.1\%) and 231 (23.7\%) participants had chat chewing and shish smoking experience respectively. Three hundred forty seven (35.6\%) of the participants had ever watched pornography. Related with assessing the participants attitude towards anal sex, 51 (5.6\%) of the participants had favorable attitude towards anal sexual practice respectively.
About $58 \%$ of study participants' perceive that youths who practice anal sex might suffer with pain. The other $17 \%$ perceived that youths who practice anal sex might have low risk of STI including HIV (Figure 1).

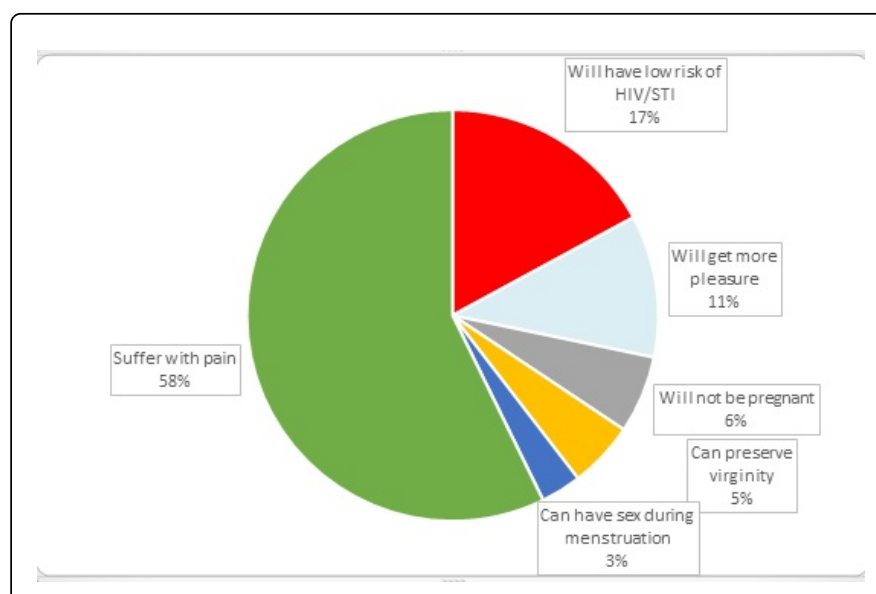

Figure 1: Youths perception on expected outcomes having anal sexual practice among preparatory school youths in Dire Dawa city administration Eastern Ethiopia, March 01-10/2016.

\section{Predictors of anal sexual experience among school youths}

As shown in Table 3 below older age (20-24 years), being male, type of school, living with other than both biological parents, parental monitoring, ever drank alcohol, ever chew chat, ever smoke shisha, ever watched pornographic movies, having favorable attitude towards anal sex practice, intimate partner having anal sex experience and ever engaged to vaginal sex were significantly associated with anal sex experience from bivariate regression analysis.

Among the peer level factors intimate partner anal sex experience was identified as strong significantly associated predictor variable for youth's anal sex practice. Youths whose intimate partner had anal sex experience were 20.48 times odds of more anal sex experience than their counterparts (COR=20.48, 95\% CI: 11.58-36.22).

Individual level factors were also assessed to determine the predictors of anal sex experience among school youths. Ever drank alcohol $\quad(\mathrm{COR}=6.68,95 \%$ CI: 3.88-11.51, p), ever chew chat ( $\mathrm{COR}=6.46,95 \% \mathrm{CI}=3.81-10.95)$, ever smoke shisha $(\mathrm{COR}=6.83,95 \%$ $\mathrm{CI}=3.96-11.78)$, ever watched pornographic movies $(\mathrm{COR}=8.51,95 \%$ $\mathrm{CI}=4.57-15.87)$, having favorable attitude towards anal sex $(\mathrm{COR}=7.39$, 95\% $\mathrm{CI}=3.78-14.47)$ and ever engaged to vaginal sex (COR=33.02, 95\% $\mathrm{CI}=15.44-70.63$ ) were significantly associated with anal sex experience from bivariate analysis.

Among the family level factors living other than biological parents $(\mathrm{COR}=3.36,95 \% \mathrm{CI}=1.46-7.74)$ and parental monitoring $(\mathrm{COR}=1.86$ 95\% CI=1.06-3.27) were also significant predictors of anal sex experience among school youths from bivariate analysis.

\section{Results from multivariate logistic regression analysis}

Variables with $\mathrm{p}$ value $<0.25$ from bivariate analysis (total of 15 variables) were selected for multivariate logistic regression analysis. First all 15 variables were entered to the multivariate model and then adjustment was made in order to identify confounders by step wise 
Citation: Alemu MT, Dessie Y, Tesfaye T, Oumer A, Teka Y (2017) Comparative Study of Pseudo-Continuous Anal Sexual Practice among Preparatory School Youths in Dire Dawa City Administration Eastern Ethiopia. J Health Educ Res Dev 5: 240. doi: $10.4172 / 2380-5439.1000240$

Page 4 of 6

backward regression method. Finally, Intimate partner engaged to anal sex, parental monitoring youth's sexual behavior, ever watched pornographic movies and ever engaged to vaginal sex were significantly associated with anal sex experience from the multivariate model.

Youths whose intimate partner engaged to anal sex were 5.34 times more likely to have anal sex experience than those whose intimate partner had no anal sex experience $(\mathrm{AOR}=5.34,95 \% \mathrm{CI}=2.39-11.9)$. Parental monitoring were identified as predictor variable for anal sex experience. Youths whose sexual behavior monitored by parents were 2.63 times more likely to have anal sex experience than those who were not monitored $(\mathrm{AOR}=2.63,95 \% \mathrm{CI}=1.12-6.19)$.
Ever watched pornographic movies were another individual level factor significantly associated with anal sex experience among school youths. Youths who ever watched pornographic movies were 3.86 times more likely to have anal sex experience than their counter parts ( $\mathrm{AOR}=3.86$ 95\% $\mathrm{CI}=1.49-10.29)$. Vaginal sex experience was also another predictor variable for anal sex practice for school youths. Youths who ever engaged in vaginal sex were 10.64 times more likely to have anal sex experience than those never engaged vaginal sex $(\mathrm{AOR}=10.64,95 \% \mathrm{CI}=4.2-26.98)$ (Table 3$)$.

\begin{tabular}{|c|c|c|c|c|c|}
\hline \multirow{2}{*}{ Variable } & & \multicolumn{2}{|c|}{ Engage in anal sex } & \multirow{2}{*}{ COR $(95 \% \mathrm{Cl})$} & \multirow{2}{*}{ AOR(95\% Cl) } \\
\hline & & Yes & No & & \\
\hline \multirow{2}{*}{ Age } & Yes & 34 & 46 & $20.48(11.58-36.22)$ & $5.34(2.39-11.9)^{*}$ \\
\hline & No & 31 & 859 & 1 & 1 \\
\hline \multirow{2}{*}{ Sex } & Yes & 19 & 171 & $1.86(1.06-3.27)$ & $2.63(1.12-6.19)^{\star}$ \\
\hline & No & 43 & 719 & 1 & 1 \\
\hline \multirow{2}{*}{ Educational status } & Yes & 40 & 194 & $6.68(3.88-11.5)$ & $1.54(.69-3.44)$ \\
\hline & No & 22 & 713 & 1 & 1 \\
\hline \multirow{2}{*}{ Type of school } & Yes & 41 & 190 & $6.46(3.8-10.95)$ & $3.38(0.98-5.17)$ \\
\hline & No & 24 & 718 & 1 & 1 \\
\hline \multirow{2}{*}{ Living arrangement } & Yes & 27 & 88 & $6.83(3.9-11.78)$ & $1.79(.80-3.99)$ \\
\hline & No & 36 & 801 & 1 & 1 \\
\hline \multirow{2}{*}{ Maternal educational } & Yes & 53 & 294 & $8.51(4.57-15.9)$ & $3.86(1.5-10.29)^{*}$ \\
\hline & No & 13 & 614 & 1 & 1 \\
\hline \multirow{2}{*}{ Paternal education } & Favorable & 15 & 36 & 7.39(3.78-14.47) & $1.38(0.47-4.00)$ \\
\hline & Unfavorable & 46 & 816 & 1 & 1 \\
\hline \multirow{2}{*}{ Intimate partner start anal sex } & Yes & 56 & 159 & $33.02(15.44-70.63)$ & $10.64(4.20-26.98)^{*}$ \\
\hline & No & 8 & 750 & 1 & 1 \\
\hline \multirow{2}{*}{ Parental monitoring } & Yes & 34 & 46 & $20.48(11.58-36.22)$ & $5.34(2.39-11.9)^{*}$ \\
\hline & No & 31 & 859 & 1 & 1 \\
\hline \multirow{2}{*}{ Ever drank alcohol } & Yes & 19 & 171 & $1.86(1.06-3.27)$ & $2.63(1.12-6.19)^{*}$ \\
\hline & No & 43 & 719 & 1 & 1 \\
\hline \multirow{2}{*}{ Ever chew chat } & Yes & 40 & 194 & $6.68(3.88-11.5)$ & $1.54(.69-3.44)$ \\
\hline & No & 22 & 713 & 1 & 1 \\
\hline \multirow{2}{*}{ Ever smoke shisha } & Yes & 41 & 190 & $6.46(3.8-10.95)$ & $3.38(0.98-5.17)$ \\
\hline & No & 24 & 718 & 1 & 1 \\
\hline \multirow{2}{*}{ Ever watch pornography } & Yes & 27 & 88 & $6.83(3.9-11.78)$ & $1.79(.80-3.99)$ \\
\hline & No & 36 & 801 & 1 & 1 \\
\hline Attitude towards anal sex & Yes & 53 & 294 & $8.51(4.57-15.9)$ & $3.86(1.5-10.29)^{*}$ \\
\hline
\end{tabular}


Citation: Alemu MT, Dessie Y, Tesfaye T, Oumer A, Teka Y (2017) Comparative Study of Pseudo-Continuous Anal Sexual Practice among Preparatory School Youths in Dire Dawa City Administration Eastern Ethiopia. J Health Educ Res Dev 5: 240. doi: $10.4172 / 2380-5439.1000240$

Page 5 of 6

No

13
614 1
1

Table 3: Factors associated with Anal sex experience among preparatory school youths in Dire Dawa city administration March 01-10/2016 $(\mathrm{N}=983)$. Note: ${ }^{*}$ shows significant association.

\section{Discussion}

In this study the proportion of youths engaged to anal sex was $6.7 \%$. This finding is greater than study conducted in Addis Ababa among school youths which was $4.3 \%$ anal sex practice [1] and very much lower than studies in America and United Kingdom which the proportion of school youths who practice $56 \%$ anal sex [13]. Similarly, anal sexual experience in this study lower than studies in Brazil and USA Texas which was $43.3 \%$ and $18 \%$ respectively [14,15]. The variation for this could be the difference in period of study and difference in study area.

More over significant proportion of youths practice anal sex without protective measures. Only $34.8 \%$ of youths using condom consistently during anal sex practice respective; the remaining large proportion of youths practiced anal sexual behavior without using protection measures. This finding is consistent with previous study conducted in Addis Ababa; only 26.1\% youths were using condom consistently during anal sexual practice [1]. The reason might be youth's low awareness on risk of STI and HIV through such sexual practice. But the risk of acquiring HIV during anal sex practice is 20 times higher than vaginal sex practice [9]. Moreover, majority of youths had multiple sexual partner for oral and anal sex practice (56.5\% of youths had more than one sexual partner for anal sex practice).

This finding is consistent with the previous study conducted in Addis Ababa (51.1\% youths had multiple anal sexual partners) [1]. This indicates that those youths who had anal sexual experience were prone for risk of acquiring STI including HIV. Therefore youths need tailored sexual and reproductive health information in order to make appropriate decision making related to their sexual activity.

The finding of this study shows $22.1 \%$ of school youths ever engaged in vaginal sex experience. This finding is comparable with other previous studies, which was engagement to sexual intercourse among school youths ranges $24.1 \%-67.7 \%$ [16-18]. Even though the proportion of sexually active youths from this study appears lower than previous findings, only $44.4 \%$ of them were using condom consistently during sexual activity and $12 \%$ of ever engaged in vaginal sex youths, had sex with commercial sex workers. Evidence-based sexual health education programs are effective in decreasing youth sexual risk behaviors, including delaying the onset of sexual activity and increasing the use of condoms among youth who are sexually active [19].

Youths whose intimate partner practice anal sex were 5.34 times more likely to had anal sexual experience than those whose intimate partner hadn't anal sex experience (95\% CI: 2.39-11.9). This finding is consistent with previous study conducted in Addis Ababa Ethiopia [1]. During youth stage Peers are main source of information rather than families and teachers. Sexual and reproductive issues are among the information shared by youths. Such information wiser good or bad circulates among peers. After a while this age group shares similar characteristics. School based sex education focusing in this social environment is very crucial to diminish risk related to anal sex practice.
Unexpectedly, unlike other study conducted in Addis Ababa [1], anal sexual experience was seen more commonly among youths who had parental monitoring among school youths. This difference in the findings might be due to; the average student age in the previous study was younger than the current sample and younger students might be more likely than older adolescents to have family as more influential of their risk behaviors than peers. In other ways the information that parents provide to their children may not tailored. Even though parents' monitor the sexual behavior of youths, the information they provide may not address important components of sexuality education. So that the information youths get from peers may divert youth's decision making.

The odds of youths who had anal sexual experience were higher among youths who ever watched pornographic movies. Youths ever watched pornographic movies were 3.86 times more likely to have anal sexual experience than those youths who hadn't ever watched pornographic movies ( $\mathrm{AOR}=3.86,95 \% \mathrm{CI}$ : $1.45-10.29)$. Youths require information, and education related with sexuality to identify risks and benefits while they were watching movies.

From this study ever engaged to vaginal sex were significantly associated with anal sexual experience among school youths. Youths ever engaged in vaginal sex had 10.64 times more odds of anal sexual experience than youths who haven't ever engaged in vaginal sex ( $\mathrm{AOR}=10.64,95 \%: 4.20-26.98)$. This finding is consistent with study conducted in India [20].

\section{Conclusion}

Considerable proportion of youths were being involved in anal sex experience with majority did not experience consistent condom use and had multiple anal sex partners. All the above realities make youths as one of the most vulnerable for STI burden especially HIV/AIDS. High burden of anal sex was seen among youths having anal sex friend, engaged in substance abuse, watching pornography and favorable attitude towards anal sex.

Sexual health education programs need to be designed and promoted to decrease youths sexual risk behaviors, including delaying the onset of sexual activity and increasing the use of condoms among youth who are sexually active. Proper emphasis need to be given to decrease these risky sexual behaviors among those youths who already engaged in oral and anal sex and to prevent others from starting these sexual behaviors.

Ethics approval and consent to participate: Ethical clearance was obtained from Haramaya University institutional health research ethics and review committee (IHRERC) and permission to collect data was obtained from each schools administration. Written and signed consent obtained from each student (age $>18$ years) and assent was taken from their parents (age $<18$ Years). 
Citation: Alemu MT, Dessie Y, Tesfaye T, Oumer A, Teka Y (2017) Comparative Study of Pseudo-Continuous Anal Sexual Practice among Preparatory School Youths in Dire Dawa City Administration Eastern Ethiopia. J Health Educ Res Dev 5: 240. doi: $10.4172 / 2380-5439.1000240$

Page 6 of 6

\section{Availability of Data and Material}

The datasets used and/or analyzed during the current study are available from the corresponding author on reasonable request.

\section{Authors' Contributions}

MTA participated from Inception to final report writing, YD \& TG participated in reviewing the proposal and final report writing, $\mathrm{AO}$ participated in data management, report writing and manuscript preparation.

\section{Acknowledgements}

We would like to thank Haramaya University, data collectors, Study participants and for those all who make this work happen.

\section{References}

1. Amsale C, Yemane B (2012) Oral and anal sex practices among high school youth in Addis Ababa, Ethiopia. BMC Public Health 12: 5.

2. Halpern CT, Haydon AA (2012) Sexual Timetables for Oral-Genital, Vaginal, and Anal Intercourse: Sociodemographic Comparisons in a Nationally Representative Sample of Adolescents. American Journal of Public Health 102: 1221-1228.

3. UNAIDS (Joint United Nations for AIDS program) (2014) Global AIDS Response Progress Reporting, 2014. Geneva, UN.

4. UN (United Nations) (2012) Revision of World Population Prospects from the United Nations.

5. CSA (Centeral Stastistical Agencey) (2014) Ethiopia Mini Demographic and Health Survey. Addis Ababa, Ethiopia, Central Statistical Agency.

6. UN (United Nations) (1994) Programme of Action adopted at the International Conference on Population and Development. Cairo, United Nations.

7. Magadi M (2006) Poor pregnancy outcomes among adolescents in South Nyanza region of Kenya. African Journal of Reproductive Health 10: 26-38.
8. ECSA (Ethiopian Centeral Stastical Agency) and ICF International (2012) Ethiopia Demographic and Health Survey 2011. Addis Ababa, Calverton, Maryland, Ethiopian Central Statistical Agency and ICF International.

9. Boily M, Baggley R, Wang L, Masse B, White R, et al. (2009) Heterosexual risk of HIV-1 infection per sexual act: Systematic review and metaanalysis of observational studies. Lancet Infectious Disease 9: 118-29.

10. Halpern-Felsher BL, Cornell JL, Kropp RY, Tschann JM (2005) Oral versus vaginal sex among adolescents: Perceptions, attitudes, and behavior. Pediatrics 115: 845-851.

11. Brady SS, Halpern-Felsher BL (2007) Adolescents' Reported Consequences of Having Oral Sex Versus Vaginal Sex. Pediatrics 119: 229-238.

12. Wikipedia (2017) Dire Dawa. Accessed on November 2015.

13. Dake J, Price J, Ward B, Welch P (2011) Midwestern rural adolescents' oral sex experience. Journal of School Health 81: 159-165.

14. Heilborn ML, Cabral CS (2006) Sexual practices in youth: analysis of lifetime sexual trajectory and last sexual intercourse. Cad Saúde Pública 22: 1471-1481.

15. Markham C, Peskin M, Hernandez BF, Johnson K, Addy RC (2011) Adolescent Sexual Behavior: Examining Data from Texas and the USA. Journal of Applied Research on Children: Informing Policy for Children at Risk 2: 1-29.

16. Dekeke G, Sandy P (2014) Factors influencing Sexual Risk Behaviors among Senior Secondary School Students (Youths). International Journal of Scientific and Research Publications 4: 1-32.

17. Kejela G, Saboka B (2015) Assessment of Knowledge, Attitude and Preventive Practices towards Sexually Transmitted Infections among Preparatory School Students in Shone Town, Southern Ethiopia. Journal of Health and Medical Information 6: 1-6.

18. Mulatu A, Tefera B, Tizta T, Muluwas A (2015) Risky Sexual Behavior and Associated Factors Among High School Youth in Pawe Woreda Benishangul Gumuz Region. Science Journal of Clinical Medicine 4: 67-75.

19. All In (2015) End Adolescent AIDS.

20. Hensel DJ, Fortenberry JD, Orr DP (2010) Factors Associated with Event Level Anal Sex and Condom Use during Anal Sex among Adolescent Women. Journal of Adolescent Health 46: 232-237. 